OPEN ACCESS

Edited by:

Antonio Gambardella,

Magna Græcia University, Italy

Reviewed by:

Elsa Fabbretti,

University of Nova Gorica, Slovenia

Victor Anggono,

The University of Queensland,

Australia

*Correspondence:

Tae-Cheon Kang

tckang@hallym.ac.kr

Received: 03 June 2017

Accepted: 21 August 2017

Published: 01 September 2017

Citation:

Kim J-E and Kang T-C (2017) p47Phox/CDK5/DRP1-Mediated

Mitochondrial Fission Evokes PV Cell

Degeneration in the Rat Dentate

Gyrus Following Status Epilepticus.

Front. Cell. Neurosci. 11:267.

doi: 10.3389/fncel.2017.00267

\section{p47Phox/CDK5/DRP1-Mediated Mitochondrial Fission Evokes PV Cell Degeneration in the Rat Dentate Gyrus Following Status Epilepticus}

\author{
Ji-Eun Kim and Tae-Cheon Kang* \\ Department of Anatomy and Neurobiology, Institute of Epilepsy Research, College of Medicine, Hallym University, \\ Chuncheon, South Korea
}

Parvalbumin (PV) is one of the calcium-binding proteins, which plays an important role in the responsiveness of inhibitory neurons to an adaptation to repetitive spikes. Furthermore, PV neurons are highly vulnerable to status epilepticus (SE, prolonged seizure activity), although the underlining mechanism remains to be clarified. In the present study, we found that p47Phox expression was transiently and selectively increased in PV neurons $6 \mathrm{~h}$ after SE. This up-regulated p47Phox expression was accompanied by excessive mitochondrial fission. In this time point, CDK5-tyrosine 15 and dynamin-related protein 1 (DRP1)-serine 616 phosphorylations were also increased in PV cells. Apocynin (a p47Phox inhibitor) effectively mitigated PV cell loss via inhibition of CDK5/DRP1 phosphorylations and mitochondrial fragmentation induced by SE. Roscovitine (a CDK5 inhibitor) and Mdivi-1 (a DRP1 inhibitor) attenuated SE-induced PV cell loss by inhibiting aberrant mitochondrial fission. These findings suggest that p47Phox/CDK5/DRP1 may be one of the important upstream signaling pathways in PV cell degeneration induced by SE via excessive mitochondrial fragmentation.

Keywords: apocynin, epilepsy, mitochondria, mitochondrial fragmentation, roscovitine, TUNEL

\section{INTRODUCTION}

Temporal lobe epilepsy (TLE) is the progressive development of spontaneous recurrent seizures pathologically characterized by specific morphological and cellular alterations (Kang et al., 2006; Kim et al., 2008, 2011). The neuronal death has been a focus of interest in TLE research since specific patterns of neuron loss occur both in principal neurons and in interneurons (Kang et al., 2006; Soukupová et al., 2014). Parvalbumin (PV) is one of the calcium-binding proteins, which are spatial and temporal control of calcium transients across membranes and inside the cytoplasm (Celio, 1990). PV expresses in $\gamma$ - aminobutyric acid (GABA)-ergic interneurons, mainly in basket cells and axoaxonic cells (Celio, 1990). Since PV regulates the fast-spiking capability of the GABAergic neurons, it plays an important role in the responsiveness of inhibitory neurons to an adaptation to repetitive spikes (Cammarota et al., 2013; Elgueta et al., 2015). Furthermore, PV neurons are extremely vulnerable to status epilepticus (SE, prolonged seizure activity). Indeed, PV neurons are very rapidly degenerated in the hilus of the dentate gyrus 1 day after SE (Soukupová et al., 2014). Therefore, PV neuron loss allows the development of uncontrolled discharges in the epileptic hippocampus. However, the underlining mechanisms for a selective PV cell loss induced by SE remain to be clarified. 
Oxidative stress by reactive oxygen species (ROS) appears to be one of the factors contributing to the pathogenesis of neuronal damages in TLE. ROS is generated during normal cellular respiration/metabolic process as well as by specific enzymes such as NADPH oxidase (Nox). Nox is a multi-component enzyme and is composed of the three cytosolic proteins, p40Phox, p47Phox, and p67Phox, and two membrane proteins, which include gp91Phox and p22Phox. In resting stage, Nox components are spatially separated and the complex inactive. In active stage, Nox components form complex, translocate to the membrane, and synthesize ROS (Bedard and Krause, 2007; Brandes et al., 2014). Although apocynin (a p47Phox inhibitor; 't Hart et al., 1990; Stolk et al., 1994) exhibits neuroprotection in pilocarpine-induced SE models (Pestana et al., 2010; Di Maio et al., 2011) and methamphetamine (MA)-mediated neuronal toxicity (Dang et al. (2016), the role of Nox-mediated ROS synthesis in the selective vulnerability of PV neurons are not completely understood. Therefore, the aims of this study were: (1) to identify whether enhanced Nox activity practically involves a selective PV neuronal loss following SE; and (2) to elucidate the molecular and cellular events responsible for Nox-mediated PV neuron degeneration. Here, we demonstrate that SE transiently up-regulated $\mathrm{p} 47 \mathrm{Phox}$ expression in PV neurons, which promoted cyclin-dependent kinase 5 (CDK5) activation. In turn, CDK5 activation degenerated PV neurons by excessive dynamin-related protein 1 (DRP1)-mediated mitochondrial fission. Therefore, these findings suggest that p47Phox/CDK5/DRP1-mediated mitochondrial fission may play an important role in loss of PV neurons following SE.

\section{MATERIALS AND METHODS}

\section{Experimental Animals and Chemicals}

Male Sprague-Dawley (SD) rats (7 weeks old) were kept under controlled environmental conditions $\left(23-25^{\circ} \mathrm{C}, 12 \mathrm{~h}\right.$ light/dark cycle) with free access to water and standard laboratory food. All animal protocols were approved by the Administrative Panel on Laboratory Animal Care of Hallym University that comply with NIH Guide for the Care and Use of Laboratory Animals. All possible efforts were taken to avoid animals' suffering and to minimize the number of animals used during the experiment. All reagents were obtained from Sigma-Aldrich (St. Louis, MO, United States), except as noted.

\section{Intracerebroventricular Infusion}

Under Isoflurane anesthesia (3\% induction, 1.5 - 2\% for surgery and $1.5 \%$ maintenance in a 65:35 mixture of $\mathrm{N}_{2} \mathrm{O}: \mathrm{O}_{2}$ ), animals were stereotaxically implanted a brain infusion kit 1 (Alzet, Cupertino, CA, United States) into the right lateral ventricle (1 $\mathrm{mm}$ posterior; $1.5 \mathrm{~mm}$ lateral; $-3.5 \mathrm{~mm}$ depth to the bregma). The infusion kit was sealed with dental cement and connected to an osmotic pump (1007D, Alzet, Cupertino, CA, United States) containing (1) vehicle, (2) apocynin (150 $\mu \mathrm{M})$, (3) roscovitine $(100 \mu \mathrm{M})$ or (4) Mdivi-1 (50 $\mu \mathrm{M})$. In a pilot study and our previous study (Hyun et al., 2017), the concentration of each compound could not affect the seizure latency and its severity in response to pilocarpine. Osmotic pump was placed in a subcutaneous pocket in the interscapular region.

\section{SE Induction}

Three days after surgery, $\mathrm{LiCl}$ ( $3 \mathrm{mEq} / \mathrm{kg}$, i.p.) was administrated to all rats $24 \mathrm{~h}$ before an injection of pilocarpine (pilocarpine hydrochloride, $30 \mathrm{mg} / \mathrm{kg}$, i.p.) in the experimental groups or saline (vehicle) in the control group. All animals were given a subcutaneous injection of atropine methylbromide ( $5 \mathrm{mg} / \mathrm{kg}$, i.p.) $20 \mathrm{~min}$ before pilocarpine or saline (control). Two hours after SE onset, diazepam (Valium; Hoffman la Roche, Neuilly sur-Seine, France; $10 \mathrm{mg} / \mathrm{kg}$, i.p.) was administered and repeated, as needed.

\section{Tissue Processing}

At the designated time points (control, $6 \mathrm{~h}$ and $12 \mathrm{~h}$ after SE induction), rats were perfused transcardially first with phosphate-buffered saline (PBS) followed by a fixative solution (4\% paraformaldehyde in $0.1 \mathrm{M}$ phosphate buffer, $\mathrm{pH} 7.4$ ) during $30 \mathrm{~min}$ under urethane anesthesia $(1.5 \mathrm{~g} / \mathrm{kg}$, i.p.). The brains were removed and submerged in the same fixative solution for $4 \mathrm{~h}$ at $4^{\circ} \mathrm{C}$. Following postfixation, brains were cryoprotected overnight in $30 \%$ sucrose solution (in $0.1 \mathrm{M} \mathrm{PBS}$ ), and sectioned with a cryostat at $30 \mu \mathrm{m}$, and consecutive sections were contained in six-well plates containing PBS.

\section{Immunohistochemistry and TUNEL Staining}

Free-floating sections were first incubated with 10\% normal goat serum (Vector, Burlingame, CA, United States) in PBS for $30 \mathrm{~min}$ at room temperature. Sections were then incubated in the mixture of primary antibodies in Table 1 (in PBS containing $0.3 \%$ triton $\mathrm{X}-100$ ) at room temperature for overnight. After washing in PBS, sections were incubated for $1 \mathrm{~h}$ in a FITC- or Cy3-conjugated secondary antiserum (Kim and Kang, 2015). To analyze the neuronal damage, we also performed TUNEL staining with the TUNEL apoptosis detection kit (Merck Millipore, Billerica, MA, United States) according to the manufacturer's instructions, before p47Phox immunofluorescence staining. For nuclei counterstaining, Vectashield mounting medium with DAPI (Vector, Burlingame, CA, United States) was used as a mountant. Some sections (reacted with $\mathrm{p} 47 \mathrm{Phox}$ antibody and PV antibody) were reacted with biotinylated secondary antiserum and ABC complex. Thereafter, immunoreactivity was developed by standard $\mathrm{DAB}$ reaction. The antibody that was preincubated with pre-immune serum was used as for negative control. As the result of negative control test, no immunoreactive structure was observed (data not shown). Images were captured using an AxioImage M2 microscope or a confocal laser scanning microscope (LSM 710, Carl Zeiss Inc., Oberkochen, Germany).

\section{Subcellular Fraction and Western Blots}

To analyze subcellular localization of p47Phox, we used subcellular Protein Fractionation Kit for Tissues (Thermo 
scientific, Waltham, MA, United States), according to the manufacturer's instructions. Thereafter, the protein concentration in the supernatant was determined using a Micro BCA Protein Assay Kit (Pierce Chemical, Rockford, IL, United States). Western blotting was performed according to standard procedures. Briefly, Tissue lysate proteins were blotted onto nitrocellulose transfer membranes, then incubated with rabbit-anti $\mathrm{p} 47 \mathrm{Phox}$ as a primary antibody (Table 1). Immunoreactive bands were detected and quantified on ImageQuant LAS4000 system (GE Healthcare, Piscataway, NJ, United States). The rabbit anti- $\beta$-actin primary antibody (for cytosolic fraction) or rabbit anti-N cadherin (for membrane fraction) was used as internal reference (Table 1).

\section{Cell Count and Measurement of Mitochondrial Length}

Images of the dentate gyrus were captured (15 sections per each animal), and areas of interest $\left(1 \times 10^{5} \mu \mathrm{m}^{2}\right)$ were selected Thereafter, immunoreactive neurons were counted on $20 \times$ images using AxioVision Rel. 4.8 Software. Individual mitochondrion length in PV cells ( $n=20 /$ section) was measured by using ZEN lite software (Blue Edition, Carl Zeiss Inc., Oberkocken, Germany) following 3D-reconstruction: Based on our previous study (Ko et al., 2016), twenty five serial images (z-stack, $1 \mu \mathrm{m}$ ) were obtained from each hippocampal section. Serial images were stacked, alighned, visualized and converted to $3 \mathrm{D}$ images using $\mathrm{ZEN}$ lite program. Thereafter, individual mitochondrial length (long axis) was measured. Two different investigators who were blind to the classification of tissues performed cell counts and measurement of mitochondrial length.

\section{Quantification of Data and Statistical Analysis}

All data were analyzed using Mann-Whitney test or ANOVA to determine statistical significance. Bonferroni's test was used for post hoc comparisons. A p-value below 0.05 was considered statistically significant.

TABLE 1 | Primary antibodies used in the present study.

\begin{tabular}{llll}
\hline Antigen & Host & $\begin{array}{l}\text { Manufacturer } \\
\text { (catalog number) }\end{array}$ & $\begin{array}{l}\text { Dilution } \\
\text { used }\end{array}$ \\
\hline $\begin{array}{lll}\text { B-actin } \\
\text { Mitochondrial marker }\end{array}$ & Mouse & Abcam (\#ab14705) & $1: 500$ (IF) \\
(Mitochondrial complex & & & \\
IV subunit 1, MTCO1) & & & \\
N-Cadherin & Rabbit & Abcam (\#ab18203) & $1: 1000$ (WB) \\
p47Phox & Rabbit & ABBIOTEC (\#252159) & $1: 200$ (IF) 1:500 (WB) \\
pCDK5-Y15 & Rabbit & GeneTex (\#GTX 32375) & $1: 100$ (IF) \\
pDRP1-S616 & Rabbit & Cell Signaling (\#4494) & $1: 500$ (IF) \\
PV & Mouse & Millipore (\#MAB1572) & $1: 1000$ (IF) \\
PV & Goat & Swant (\#PVG213) & $1: 100000$ (IF)
\end{tabular}

\section{RESULTS}

\section{p47Phox-Mediated PV Cell Loss Following SE}

Figure 1 shows that $\mathrm{p} 47 \mathrm{Phox}$ expression was selectively increased in hilar neurons $6 \mathrm{~h}$ after SE, as compared to control animals ( $p<0.05$ vs. control animals, Figures 1A,B). This up-regulated $\mathrm{p} 47 \mathrm{Phox}$ expression disappeared in hilar neurons $12 \mathrm{~h}$ after SE $(p<0.05$ vs. control animals, Figures 1A,B). Double immunofluorescent study revealed that $80 \%$ of PV cells contained p47Phox expression $6 \mathrm{~h}$ after SE (Figures 2A,B). In addition, 20\% of $\mathrm{p} 47 \mathrm{Phox}$ positive neurons showed TUNEL positivity at this time point (Figures 2A,C), although there was no difference in the number of PV cell as compared to control (Figures 2A,D). Twelve hour after SE, the number of PV cells was significantly reduced, as compared to control (Figures 2A,D). To elucidate the role of p47Phox in SE-induced PV cell loss, we applied apocynin prior to SE induction. As compared to vehicle, apocynin attenuated SE-induced PV cell loss (Figures 2A,E). These findings indicate that disappearance of $\mathrm{p} 47 \mathrm{Phox}$ cell may be due to PV cell loss, and that transient up-regulated p47Phox may play an important role in SE-induced PV cell loss. Furthermore, apocynin inhibited up-regulation and membrane translocation of p47Phox in PV cells following SE $(p<0.05$ vs. vehicle, Figures 3A-C and Supplementary Figure 1). Since Nox activation is required for the mobilization of cytoplasmic p47Phox to dock with the membrane-bound proteins for superoxide production (Brandes et al., 2014), our findings indicate that up-regulated p47Phox may be an indicative of increased Nox activity, which is abrogated by apocynin.

\section{p47Phox-Mediated Mitochondrial Fragmentation in PV Cell Following SE}

Mitochondria are dynamic organelles that are essential for maintaining cell function and survival. Thus, impaired mitochondrial dynamics (fission and fusion) triggers neuronal death (Youle and Karbowski, 2005; Parone et al., 2008; DuBoff et al., 2012; Kim et al., 2014). Thus, we investigated whether p47Phox over-expression involves aberrant mitochondrial dynamics in PV cell following SE. In control animals, mitochondrial length was $\sim 1.13 \mu \mathrm{m}$ in PV cells (Figures 3D,E). Six $\mathrm{h}$ after SE, mitochondrial length in PV cells was reduced to $\sim 0.34 \mu \mathrm{m}$ ( $p<0.05$ vs. control, Figures 3D,E). Apocynin prevented mitochondrial fragmentation induced by SE, thus mitochondrial length was $\sim 0.78 \mu \mathrm{m}$ ( $p<0.05$ vs. vehicle, Figures 3D,E). These findings indicate a potential relationship between p47Phox over-expression and mitochondrial dynamics.

\section{p47Phox-Mediated CDK5 Activation in PV Cell Following SE}

It is well known that elevated $\mathrm{ROS}$ and $\mathrm{Ca}^{2+}$ levels occur CDK5 activation, which induces further ROS accumulation in neuronal cells (Sun et al., 2008). In the present study, 19.6\% of PV cells contained CDK5-Y15 phosphorylation in control animals (Figures 4A,B). Six hour after SE, the phosphorylation 
A
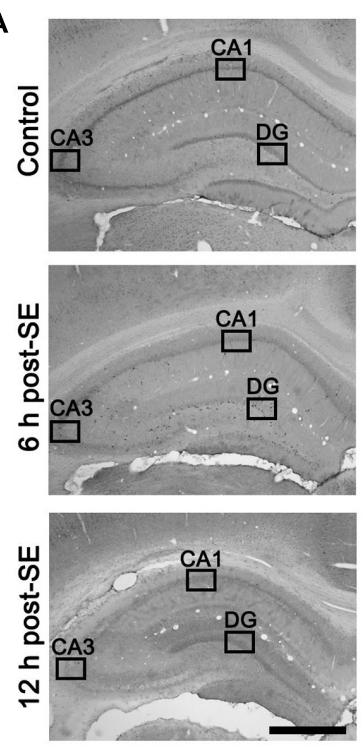

DG
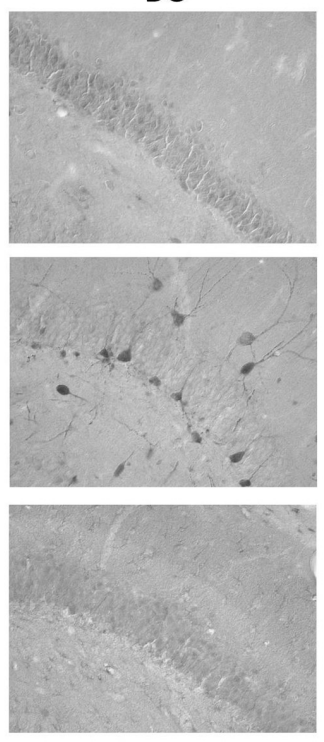

CA1
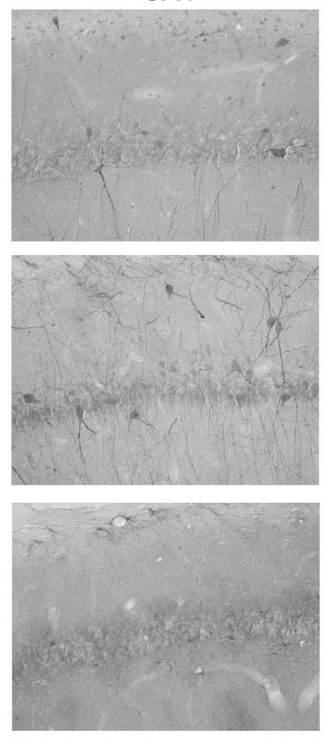

CA3
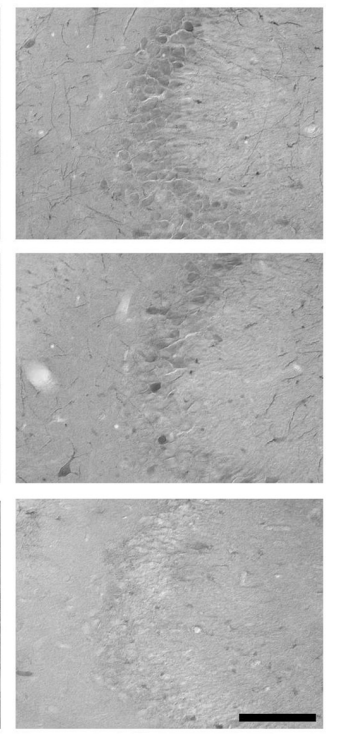

B

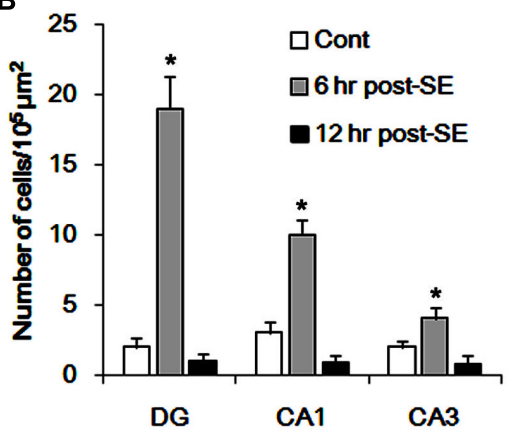

FIGURE 1 | Transient up-regulation of p47Phox in hilar neurons following SE. (A) p47Phox expression is rapidly increased in hilar neurons 6 h after SE, and disappears $12 \mathrm{~h}$ after SE. Rectangles in low magnification panels indicate the zoom areas for the high magnification photos. Bar $=400$ (Left panel) and $50 \mu \mathrm{m}$. (B) Quantification of the number of p47Phox-positive neurons. Open circles indicate each individual value. Horizontal bars indicate mean value. Error bars indicate $\mathrm{SD}\left({ }^{*} p<0.05\right.$ vs. control; $n=7$, respectively).

of CDK5-tyrosine (Y) 15 site was significantly elevated only in PV cells. Thus, $81.7 \%$ of PV cells contained CDK5-Y15 phosphorylation ( $p<0.05$ vs. control, Figures 4A,B). Apocynin effectively ameliorated SE-induced CDK5-Y15 phosphorylation in PV cells. Thus, $41.9 \%$ of PV cells showed elevated CDK5-Y15 phosphorylation ( $p<0.05$ vs. vehicle, Figures 4A,B). Roscovitine (a CDK5 inhibitor) prevented the excessive mitochondrial fission in PV cells induced by SE, as compared to vehicle $(p<0.05$ vs. control, Figures 4C,D). Furthermore, roscovitine attenuated SE-induced PV cell loss without altered p47Phox expression in PV cells ( $p<0.05$ vs. vehicle, Figures 5A-D). Thus, our findings indicate that $\mathrm{p} 47 \mathrm{Phox}$ may promote excessive mitochondrial fragmentation in PV cells by CDK5 activation.

\section{p47Phox-Mediated DRP1-S616 Phosphorylation in PV Cell Following SE}

The remaining question is how p47Phox-mediated CDK5 activation facilitated mitochondrial fragmentation in PV cells following SE. Mitochondrial dynamics are regulated by various molecules, such as mitofusin 1/2 (MFN1/2), optic atrophy 1 (OPA1) and dynamin-related proteins 1 (DRP1; Chan, 2006). Among them, DRP1 is a key molecule for mitochondrial fission (Smirnova et al., 2001). DRP1 activity is differently regulated by its phosphorylation: Serine (S) 616 site phosphorylation facilitates mitochondrial fission, but S637 site phosphorylation inhibits it (Kashatus et al., 2011). Since CDK5 triggers mitochondrial fission by increased DRP1-S616 phosphorylation (Xie et al., 2015), it is likely that p47Phox-mediated CDK5 activation may evoke excessive mitochondrial fragmentation in PV cells via DRP1-S616 phosphorylation. To confirm this hypothesis, we validated whether p47Phox activity enhances DRP1 phosphorylation in PV cells. In control animals, $22.3 \%$ of PV cells contained DRP1-S616 phosphorylation (Figures 6A,B). Six $h$ after SE, $74.7 \%$ of PV cells showed up-regulation of DRP1-S616 phosphorylation $(p<0.05$ vs. control, Figures 6A,B). 
A
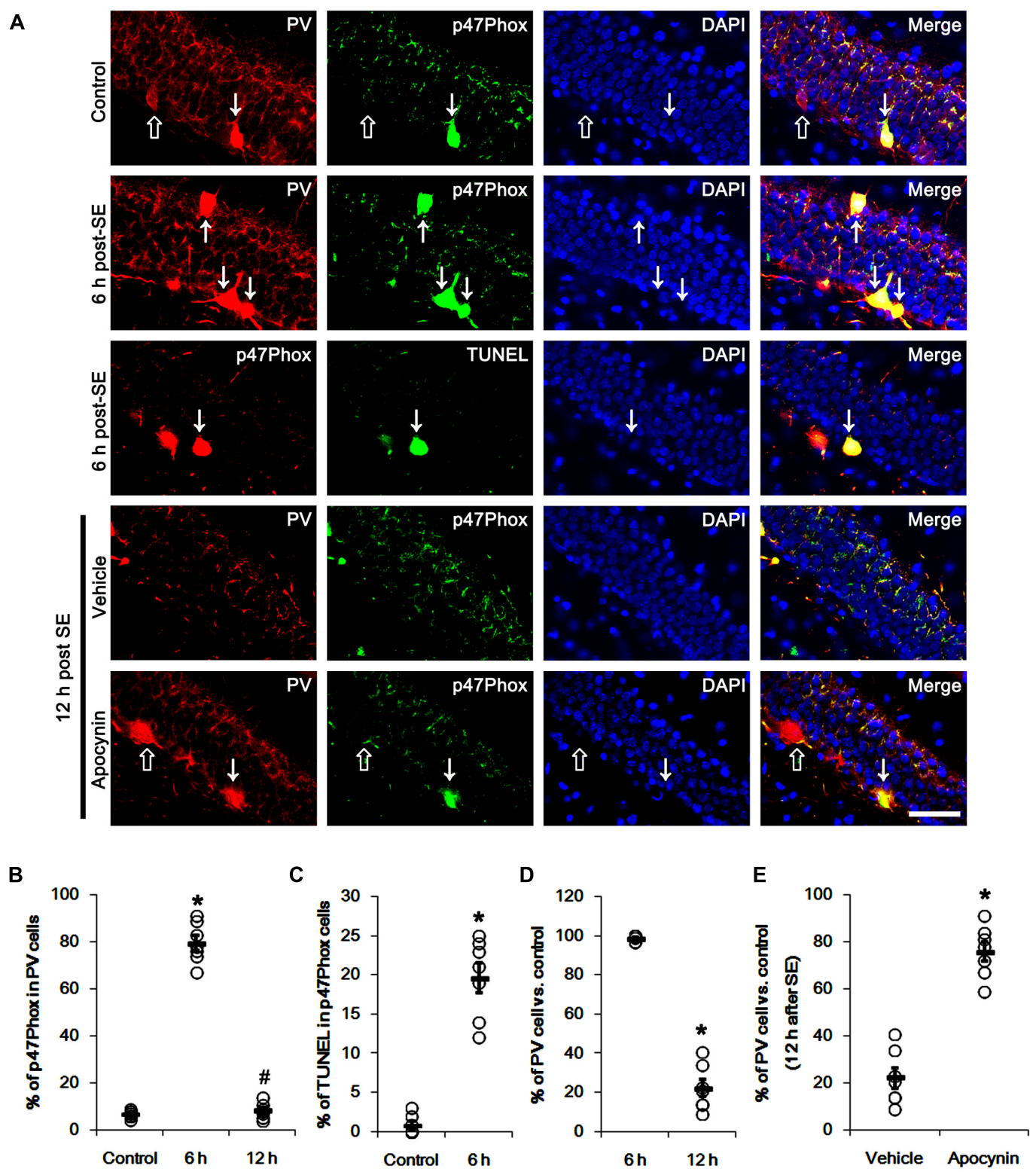

FIGURE 2 | Effect of apocynin on p47Phox expression and PV cell loss following SE. (A) Representative photos demonstrating p47Phox expression and TUNEL signal in PV cells. As compared to control, up-regulated p47Phox expression and TUNEL signal are observed in PV cells $6 \mathrm{~h}$ after SE. Apocynin attenuates SE-induced PV cell loss $12 \mathrm{~h}$ after SE. Arrows indicate PV cells showing up-regulated p47Phox expression and TUNEL signal. Open arrows indicate PV cells showing the absence of p47Phox expression. Bar $=25 \mu \mathrm{m}$. (B) Quantification of the fraction of p47Phox positive cells in PV neurons. Open circles indicate each individual value. Horizontal bars indicate mean value. Error bars indicate SEM ${ }^{*},{ }^{*} p<0.05$ vs. control and 6 h post SE-group, respectively; $n=7$, respectively). (C) Quantification of the fraction of TUNEL positive cells in PV neurons. Open circles indicate each individual value. Horizontal bars indicate mean value. Error bars indicate SEM ( ${ }^{*} p<0.05$ vs. control; $n=7$, respectively). (D) Quantification of the number of PV neurons following SE. Open circles indicate each individual value. Horizontal bars indicate mean value. Error bars indicate SEM ( ${ }^{*} p<0.05$ vs. control; $n=7$, respectively). (E) Quantification of the effect of apocynin on SE-induced PV cell loss. Open circles indicate each individual value. Horizontal bars indicate mean value. Error bars indicate SEM $(* p<0.05$ vs. vehicle; $n=7$, respectively).

Consistent with our previous study (Ko et al., 2016), DRP1-S616 phosphorylation level was also increased in astrocytes. Apocynin effectively attenuated SE-induced DRP1-S616 phosphorylation in PV cells. Thus, 35.1\% of PV cells showed enhanced DRP1-S616 phosphorylation $(p<0.05$ vs. vehicle, Figures 6A,B). However, apocynin did not affect DRP1-S616 phosphorylation in astrocytes (Figures 6C,D). To address the issue of whether an excessive mitochondrial fission leads to PV cell loss in response to SE, furthermore, we applied Mdivi-1 (a DRP1 inhibitor). Mdivi1 effectively prevented mitochondrial fragmentation in PV cells and the loss of PV neurons induced by SE $(p<0.05$ 

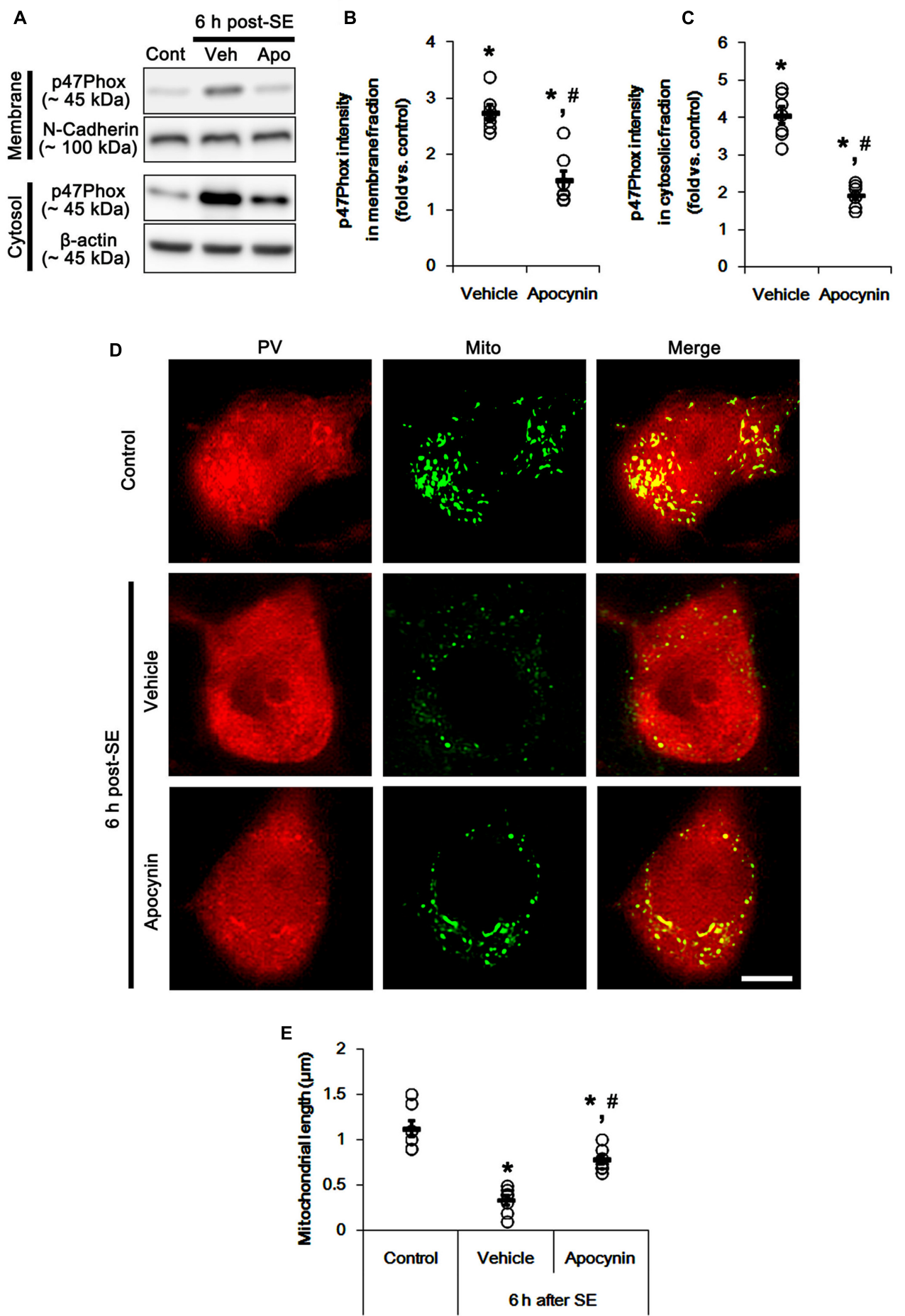

FIGURE 3 | Effect of apocynin on p47Phox translocation and mitochondrial fission induced by SE. (A) Representative western data demonstrating p47Phox subcellular locations. As compared to control animals, SE increases p47Phox expression and its membrane location. Apocynin inhibits up-regulation and membrane translocation of p47Phox following SE. (B) Quantification of the effect of apocynin on membrane p47Phox translocation following SE. Open circles indicate each individual value. Horizontal bars indicate mean value. Error bars indicate SEM (*, ${ }^{*} p<0.05$ vs. control and vehicle, respectively; $n=7$, respectively).

(C) Quantification of the effect of apocynin on cytosolic p47Phox expression following SE. Open circles indicate each individual value. Horizontal bars indicate mean value. Error bars indicate SEM $\left({ }^{*},{ }^{*} p<0.05\right.$ vs. control and vehicle, respectively; $n=7$, respectively). (D) Representative photos of mitochondria in PV cells. As compared to vehicle, apocynin attenuates SE-induced mitochondrial fragmentation in PV cells. Bar $=5 \mu \mathrm{m}$. (E) Quantification of the effect of apocynin on mitochondrial length. Open circles indicate each individual value. Horizontal bars indicate mean value. Error bars indicate SEM $\left(^{*},{ }^{*} p<0.05\right.$ vs. control and vehicle, respectively; $n=7$, respectively). 

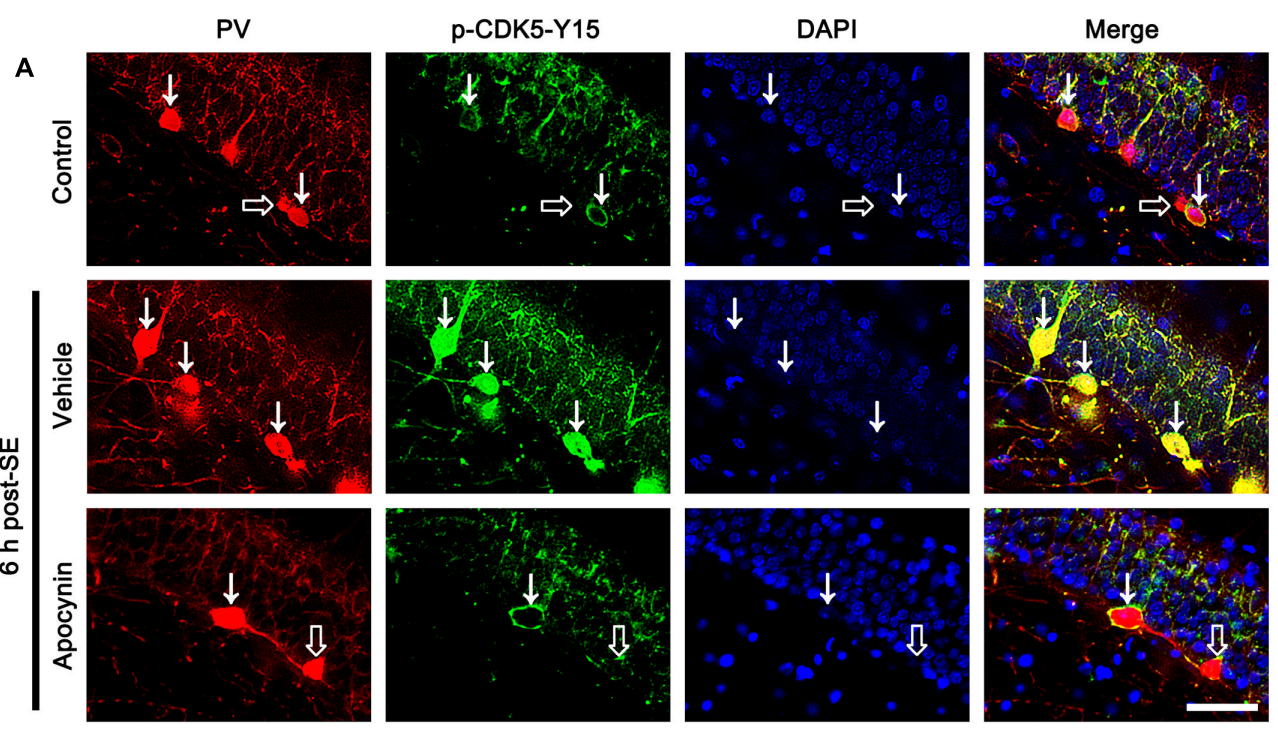

B

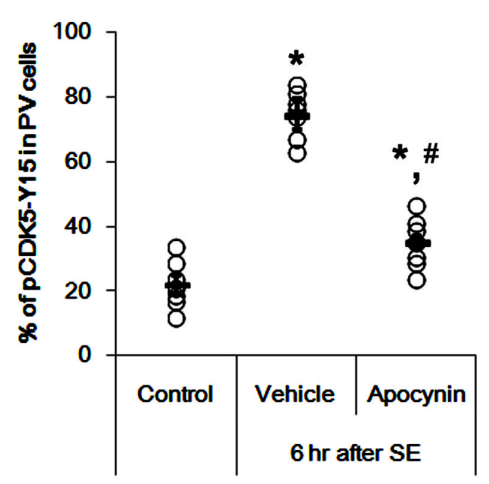

C
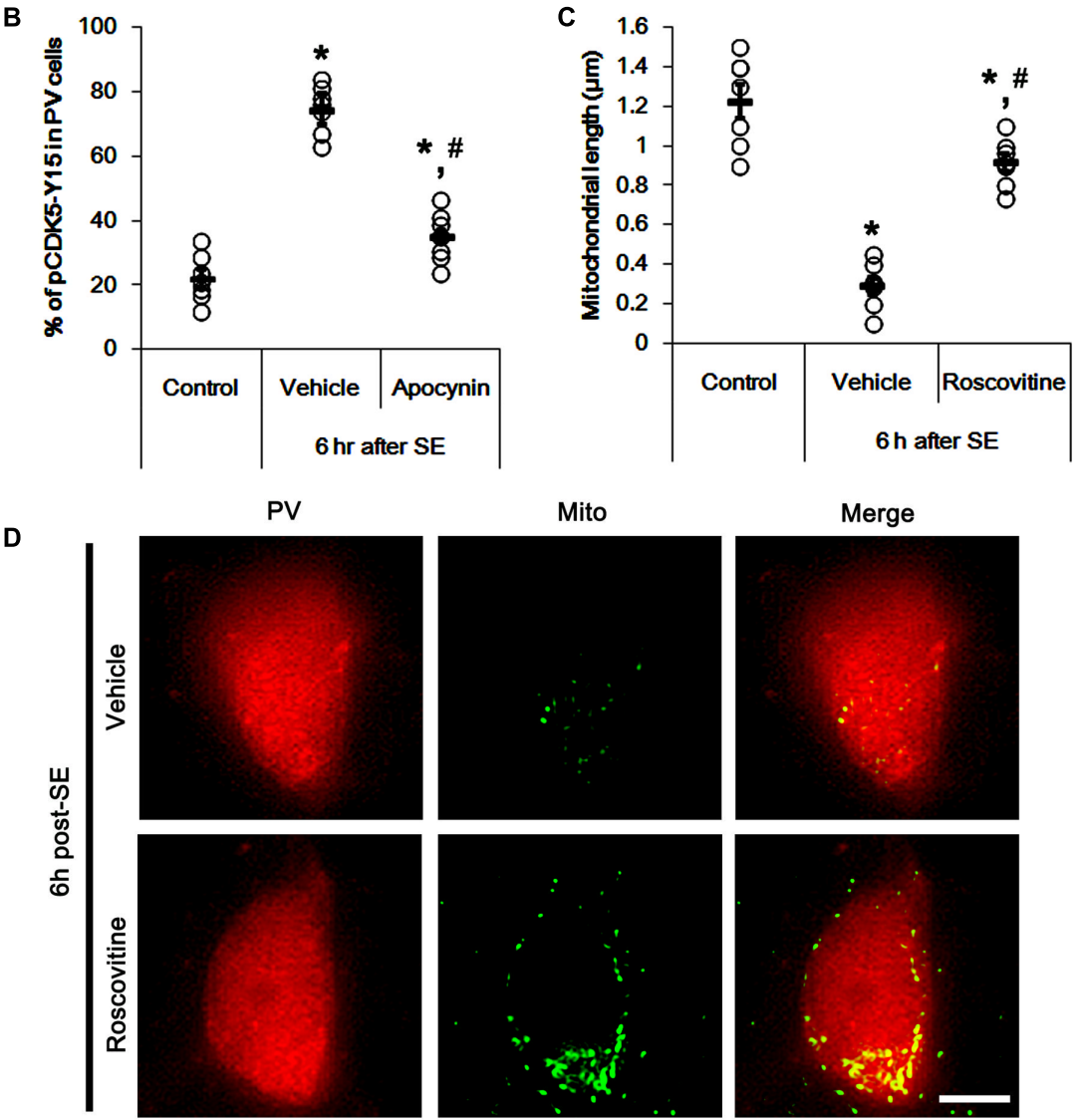

Mito
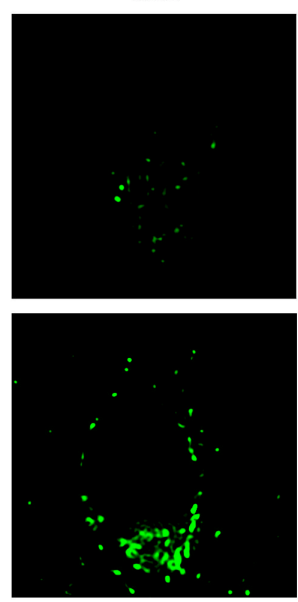

Merge
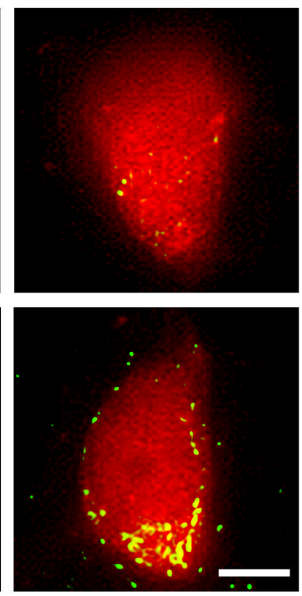

FIGURE 4 | Effect of apocynin on CDK5-mediated mitochondrial fission in PV cells induced by SE. (A) Representative photos demonstrating CDK5-Y15 phosphorylation in PV cells. As compared to control, up-regulated CDK5-Y15 phosphorylation is observed in PV cells $6 \mathrm{~h}$ after SE. Apocynin attenuates SE-induced CDK5-Y15 phosphorylation in PV cells. Arrows indicate PV cells showing up-regulated CDK5-Y15 phosphorylation. Open arrows indicate PV cells showing the absence of CDK5-Y15 phosphorylation. Bar $=25 \mu \mathrm{m}$. (B) Quantification of the fraction of CDK5-Y15 phosphorylation in PV neurons. Open circles indicate each individual value. Horizontal bars indicate mean value. Error bars indicate SEM (*, ${ }^{*} p<0.05$ vs. control and vehicle, respectively; $n=7$, respectively).

(C) Quantification the effect of roscovitine on mitochondrial length. Open circles indicate each individual value. Horizontal bars indicate mean value. Error bars indicate SEM (*, $p<0.05$ vs. control and vehicle, respectively; $n=7$, respectively). (D) Representative photos demonstrating the effect of roscovitine on mitochondrial fission in PV cells induced by SE. As compared to vehicle, roscovitine attenuates SE-induced mitochondrial fragmentation. Bar $=5 \mu \mathrm{m}$. 


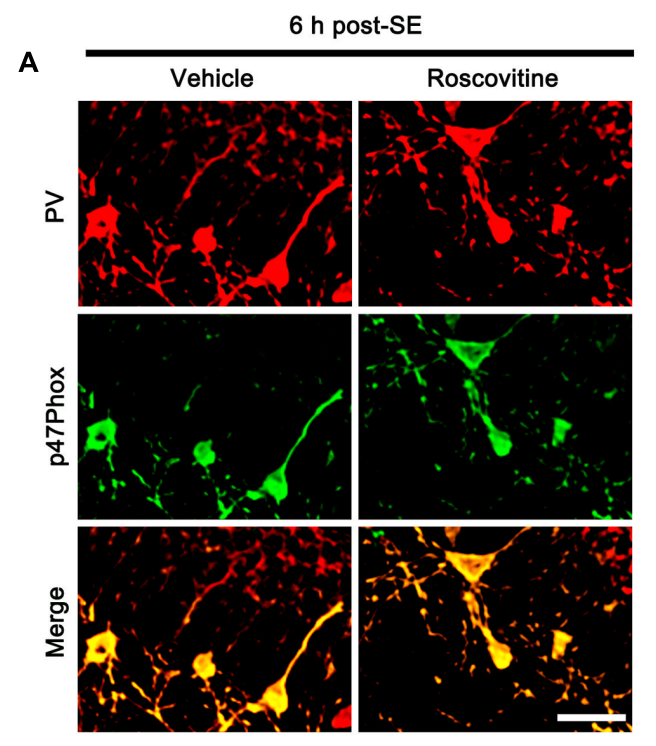

B
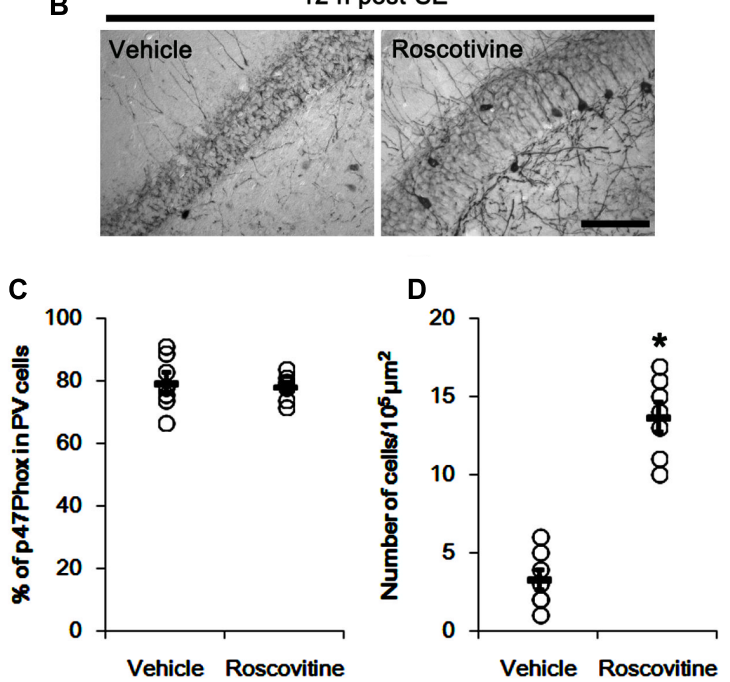

FIGURE 5 | Effect of roscovitine on p47Phox expression and PV cell loss induced by SE. (A) Representative photos demonstrating p47Phox expression in PV cells following SE. Apocynin does not affect SE-induced up-regulation of p47Phox expression. Bar $=25 \mu \mathrm{m}$. (B) Representative photos demonstrating PV cells in the dentate gyrus. Apocynin attenuates SE-induced PV cell loss. Bar $=50 \mu \mathrm{m}$. (C) Quantification the effect of roscovitine on the fraction of p47Phox in PV neurons. Open circles indicate each individual value. Horizontal bars indicate mean value. Error bars indicate SEM ( $n=7$, respectively). (D) Quantification the effect of roscovitine on PV cell loss induced by SE. Open circles indicate each individual value. Horizontal bars indicate mean value. Error bars indicate SEM $\left(^{*} p<0.05\right.$ vs. vehicle; $n=7$, respectively).

vs. vehicle), although it did not affect p47Phox expression and p-CDK5-Y15 phosphorylation (Figures 7A-H). Taken together, these findings indicate that up-regulated p47Phox expression/activity may result in mitochondrial fragmentation in PV cells by enhance DRP1-S616 phosphorylation following SE.

\section{DISCUSSION}

The major findings of the present study are that transient up-regulation of p47Phox expression responses to pilocarpineinduced $\mathrm{SE}$ evoked the rapid PV cell loss via excessive CDK5/DRP1-mediated mitochondrial fission (Figure 8).

The loss of PV cells in the hilus of the dentate gyrus is one of the most rapid and dramatic events induced by SE. The PV cell loss is already observed in the acute phase (1 day-post SE) and further worsened to less than $10 \%$ of control values 2 months after SE, which results in the decrease in GABA outflow (Soukupová et al., 2014). Since PV is responsible for the fast-spiking capability of GABAergic neurons, PV cells play an important role in the responsiveness of fast-GABAergic inhibitory transmission with a rapid adaptation in response to repetitive stimuli. Thus, the PV cell loss allows the development of uncontrolled discharges and one of important causes of epileptogenic processes (Sloviter, 1991; Sloviter et al., 2003). However, the molecular mechanisms render PV cells more vulnerable to SE are still unclear. In the present study, we found that transient up-regulation of p47Phox expression in PV cells $6 \mathrm{~h}$ after SE, and that apocynin alleviated SE-induced PV cell loss alongside the prevention of up-regulation and membrane translocation of p47Phox. These findings are consistent with previous studies demonstrating that seizure activity results in the translocation of p47Phox from hippocampal cytosol to membrane fractions (Patel et al., 2005), and Nox-derived ROS production triggers cognitive impairment through PV interneuron loss (Qiu et al., 2016; Zhang et al., 2016). Therefore, our findings indicate that transient p47Phox overexpression may be one of causes for rapid PV cell loss induced by SE.

Oxidative stress by ROS contributes to neuronal death by mitochondrial dysfunctions as well as other harmful reactions including DNA damage, protein/lipid peroxidation, protein aggregation and proteosome malfunction (Jahani-Asl et al., 2007; Zhu et al., 2007). Indeed, apocynin and p47Phox genetic inhibition attenuated MA-induced neuronal toxicity via preventing mitochondrial burdens (Dang et al., 2016). Mitochondria are dynamic organelles that continuously change their morphology through fusion and fission events in response to intracellular circumstances, which is closely linked to cell death mechanisms (Cheung et al., 2007; Detmer and Chan, 2007; Jahani-Asl et al., 2007; Chen and Chan, 2009; Rintoul and Reynolds, 2010). In particular, excessive mitochondrial fragmentations provoke the impaired mitochondrial function, which increases susceptibility to apoptotic stimuli (Campello and Scorrano, 2010). Furthermore, mitochondrial fission directly enables increased mitochondrial ROS production, and further deteriorates oxidative damage secondary to Nox-derived ROS (Yu et al., 2006, 2008). In the present 

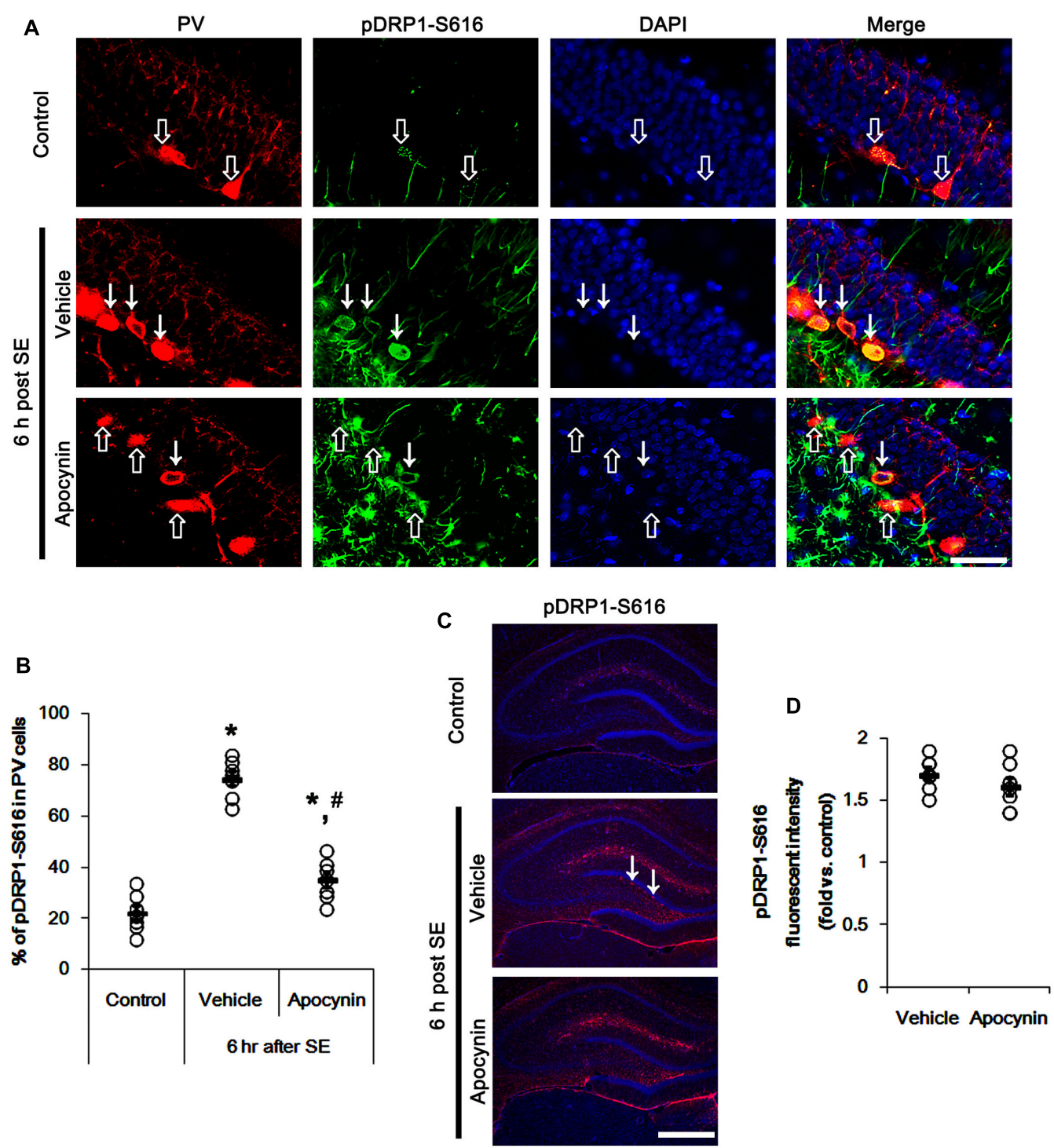

FIGURE 6 | Effect of apocynin on DRP1-S616 phosphorylation in PV cells following SE. (A) Representative photos demonstrating DRP1-S616 phosphorylation in PV cells. As compared to control, up-regulated DRP1-S616 phosphorylation is observed in PV cells $6 \mathrm{~h}$ after SE. Apocynin attenuates SE-induced DRP1-S616 phosphorylation in PV cells. Arrows indicate PV cells showing up-regulated DRP1-S616 phosphorylation. Open arrows indicate PV cells showing the absence of DRP1-S616 phosphorylation. Bar $=25 \mu \mathrm{m}$. (B) Quantification of the fraction of DRP1-S616 phosphorylation in PV neurons. Open circles indicate each individual value. Horizontal bars indicate mean value. Error bars indicate SEM $(*, \# p 0.05$ vs. control and vehicle, respectively; $n=7$, respectively). (C) Low magnification photos demonstrating DRP1-S616 phosphorylation in the hippocampus. As compared to control, up-regulated DRP1-S616 phosphorylation is observed in subgranular neurons (arrows) as well as non-neuronal cells $6 \mathrm{~h}$ after SE. Apocynin attenuates SE-induced DRP1-S616 phosphorylation in subgranular neurons, but not in non-neuronal cells. Bar $=400 \mu \mathrm{m}$. (D) Quantification of the pDRP1-S616 fluorescent intensity in non-neuronal cells. Open circles indicate each individual value. Horizontal bars indicate mean value. Error bars indicate SEM $(n=7$, respectively).

study, SE-induced p47Phox overexpression led to aberrant mitochondrial fissions by DRP1-S616 phosphorylation in PV cells. This p47Phox overexpression was accompanied by the increased CDK5-Y15 phosphorylation. Furthermore, apocynin effectively mitigated SE-induced CDK5 phosphorylation in PV cells. CDK5 is a unique CDK that plays a role in various neuronal activities unrelated to the cell cycle events, such as DRP1-S616 phosphorylation (Lai and Ip, 2009; Xie et al., 2015). Based on the ROS-mediated CDK5 activation (Sun et al., 2008) and the present data, our findings indicate that Nox-derived ROS may increase CDK5 activity and facilitate DRP1-mediated mitochondrial fission in PV cells. Indeed, inhibition of CDK5 activity abrogates the increase in mitochondrial fission by inhibiting DRP1 activity in Huntington's disease model (Cherubini et al., 2015) and NMDA-induced neuronal loss (Jahani-Asl et al., 2015). The present data also reveal that roscovitine ameliorated SE-induced excessive mitochondrial fission. In addition, 
A
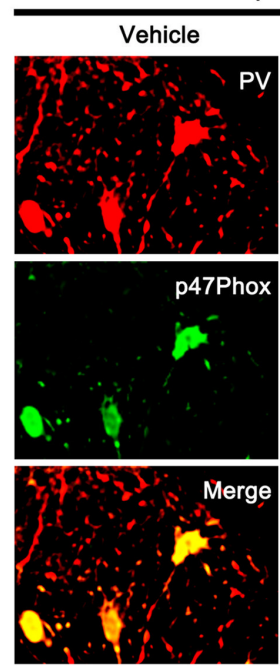

C

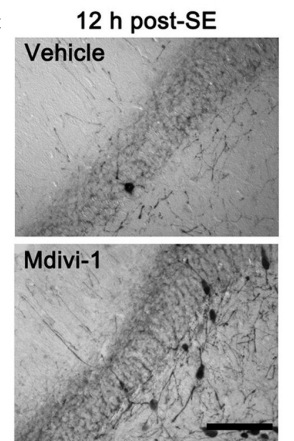

$\mathrm{h}$ post-SE
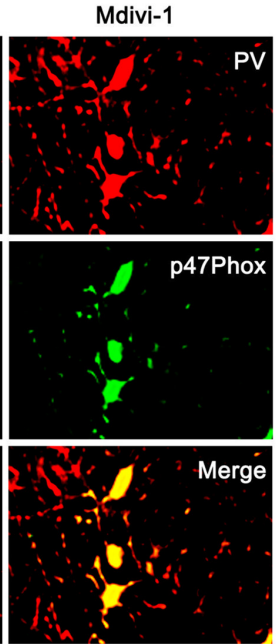

D

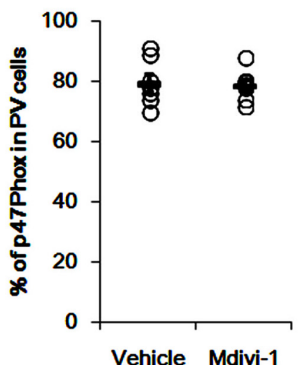

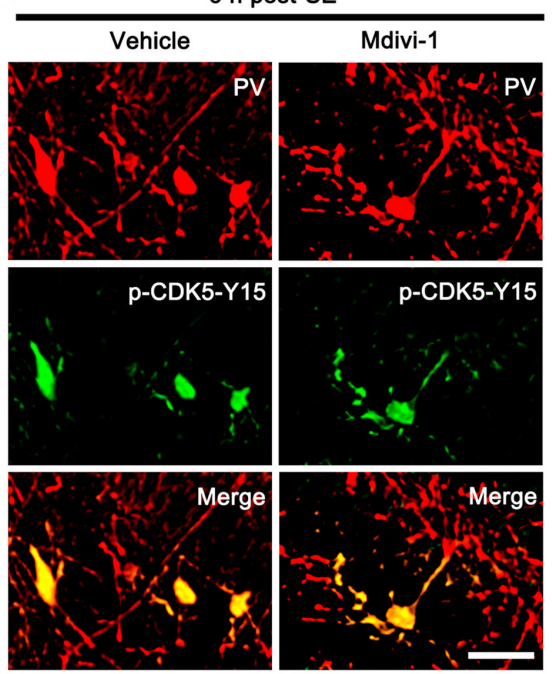

$\mathbf{E}$

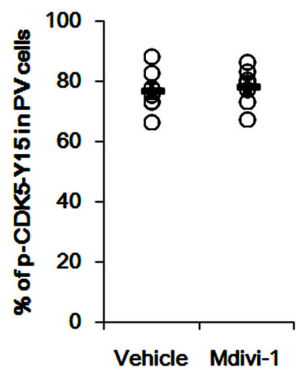

F
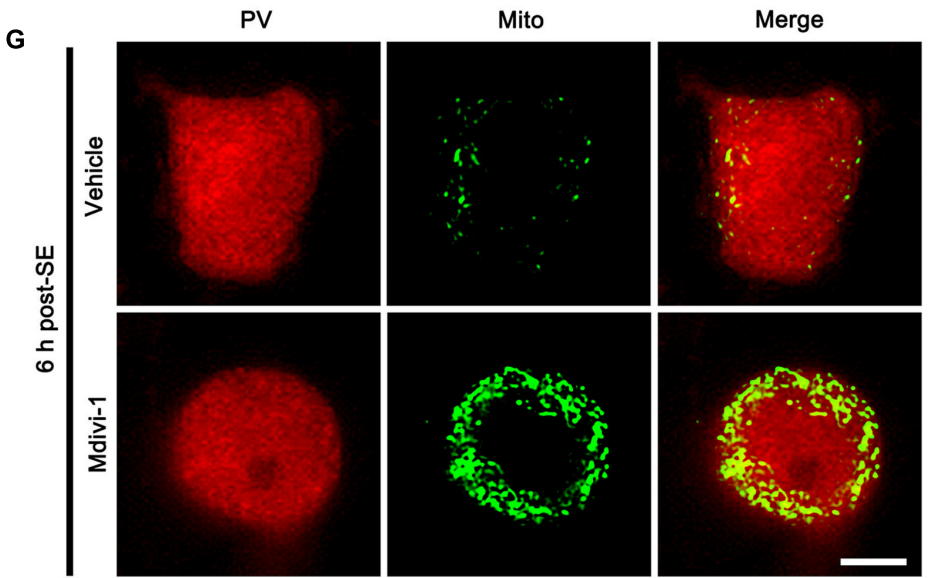

FIGURE 7 | Effect of Mdivi-1 on p47Phox expression, CDK5 phosphorylaiton and PV cell loss induced by SE. (A,B) Representative photos demonstrating the effect of Mdivi-1 on p47Phox expression and CDK5 phosphorylation in PV cells following SE. Mdivi-1 does not affect SE-induced up-regulations of p47Phox expression and CDK5 phosphorylaiton. Bar $=25 \mu \mathrm{m}$. (C) Representative photos demonstrating PV cells in the dentate gyrus. Mdivi-1 attenuates SE-induced PV cell loss. Bar $=50 \mu \mathrm{m}$. (D) Quantification the effect of Mdivi-1 on the fraction of p47Phox in PV neurons. Open circles indicate each individual value. Horizontal bars indicate mean value. Error bars indicate SEM ( $n=7$, respectively). (E) Quantification the effect of Mdivi-1 on the fraction of CDK5-Y15 phosphoryaltion in PV neurons. Open circles indicate each individual value. Horizontal bars indicate mean value. Error bars indicate SEM ( $n=7$, respectively). (F) Quantification the effect of Mdivi-1 on PV cell loss induced by SE. Open circles indicate each individual value. Horizontal bars indicate mean value. Error bars indicate SEM ${ }^{*} p<0.05$ vs. vehicle; $n=7$, respectively). (G) Representative photos demonstrating the effect of Mdivi-1 on mitochondrial fission in PV cells induced by SE. As compared to vehicle, Mdivi-1 attenuates SE-induced mitochondrial fragmentation. Bar $=5 \mu \mathrm{m}$. (H) Quantification the effect of Mdivi-1 on mitochondrial length. Open circles indicate each individual value. Horizontal bars indicate mean value. Error bars indicate SEM $\left({ }^{*} p<0.05\right.$ vs. vehicle; $n=7$, respectively). 


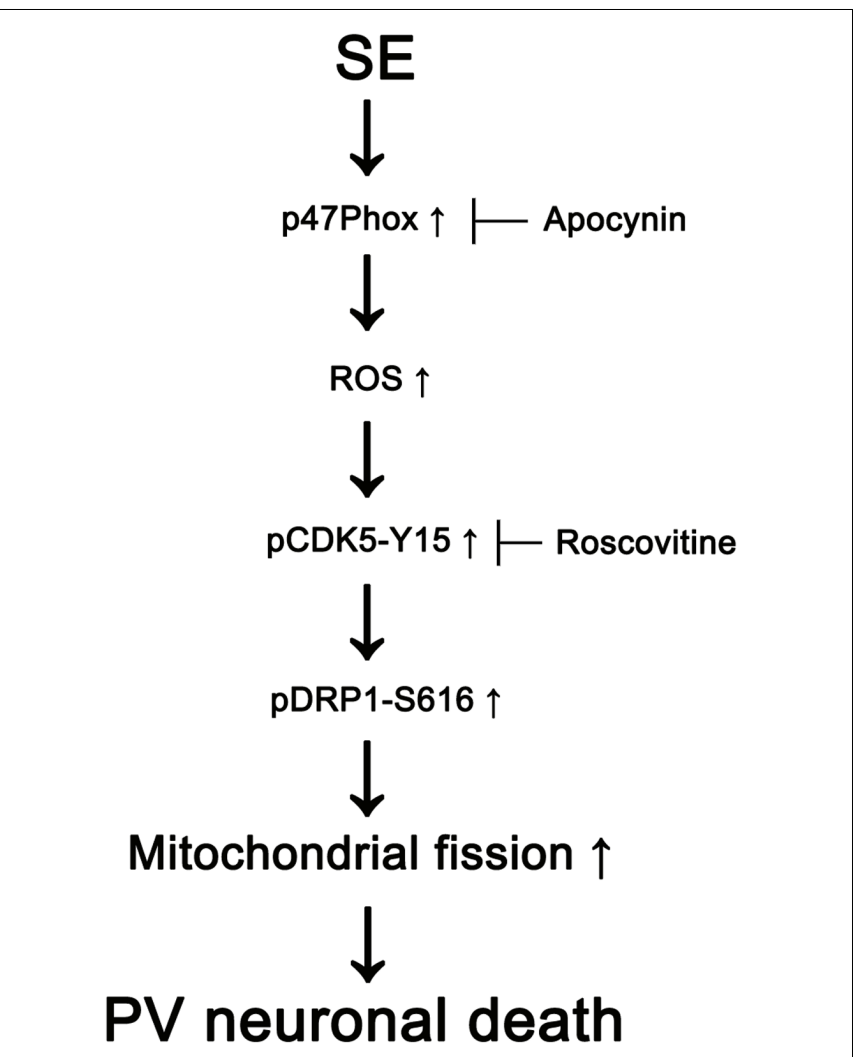

FIGURE 8 | Scheme of role of p47Phox in PV cell loss induced by SE. SE increases p47Phox activity in PV cells. Subsequently, p47Phox increases ROS synthesis. ROS-mediated CDK5 activation phosphorylates DRP1 at S616 site, which leads to PV cell loss due to excessive mithocondrial fission.

inhibition of excessive mitochondrial fission by Mdivi-1 effectively attenuated SE-induced PV cell loss without the changed p-CDK5-Y15 phosphorylation. Therefore, our findings suggest that p47Phox-mediated CDK5 activation may be one of the essential up-stream signal pathways that lead to excessive DRP1-dependent mitochondrial fragmentation in PV cells.

On the other hand, hippocampal neurons have the heterogeneous vulnerability in response to various insults. Dentate hilar neurons and CA1-3 pyramidal cell are extremely vulnerable to insults, while dentate granule cells are resistant (Ordy et al., 1993; Mathern et al., 1995; Wittner et al., 2001; Kim et al., 2011; Ryu et al., 2011). Interestingly, hippocampal neurons also show the distinct cell death patterns in the different hippocampal regions following SE: CA1 pyramidal cell death is necrotic rather than apoptotic (Kim et al., 2014; Ko et al., 2015; Hyun et al., 2016), but PV cells is caspase-3 dependent apoptotic (Kang et al., 2006). Recently, we have reported that the impaired mitochondrial fission induces programmed necrosis in CA1 pyramidal cells following SE (Kim et al., 2014; Ko et al., 2015; Hyun et al., 2016). Unlike CA1 neurons, the present study reveals that SE resulted in PV cell loss through excessive mitochondrial fragmentation, and Mdivi-1 effectively ameliorated SE-induced PV cell loss. Similar to the case of PV cell loss in the present study, inhibition of mitochondrial fission by Mdivi-1 attenuates the SE-induced neuronal death in hippocampus via suppression of the ROS-mediated mitochondrial apoptosis pathway in 60 min-SE duration models (Qiu et al., 2013; Xie et al., 2013). However, the effects of Mdivi-1 in DRP1 expression are distinctly described: Mdivi-1 attenuates SE-induced up-regulation of DRP1 expression (Qiu et al., 2013) or not (Xie et al., 2013). Regardless of the difference of models (60 min-SE induction in previous papers and $2 \mathrm{~h}$-SE duration in the present study) and the effect of Mdivi-1 on DRP1 expression, it is likely that excessive mitochondrial fission may result in apoptotic neuronal death. Therefore, our findings indicate that the underlying mechanisms of SE-induced neuronal death may be dependent on the patterns of impaired mitochondrial dynamics. Indeed, dysfunction of mitochondrial fission (aberrant mitochondrial elongation) exerts necrotic cell death via a decrease in mitochondrial bioenergetics, while excessive mitochondrial fragmentation induces apoptotic cell death (Youle and Karbowski, 2005; Parone et al., 2008; DuBoff et al., 2012; Qiu et al., 2013; Xie et al., 2013; Kim et al., 2014). Similar to neurons, SE results in the differential mitochondrial dynamics in astrocytes, which are closely relevant to the distinct astroglial responses (Ko et al., 2016). Therefore, our findings suggest that the properties of mitochondrial dynamics may be distinct from each cell subpopulation, which influences on the cell viability or cell death pattern in response to SE.

Recently, we have reported that SE enhances pDRP1-S616 level in astrocytes within molecular layer of the dentate gyrus 3 days after SE. These SE-induced DRP1-S616 phosphorylations in astrocytes are effectively attenuated by roscovitine. Thus, we have suggested that CDK5 might play an important role in DRP1-S616 phosphorylation in astrocytes following SE (Hyun et al., 2017). However, the up-stream regulators of CDK5 phosphorylation in astrocyte are still unclear. In the present study, SE also increased pDRP1-S616 level in astrocytes $6 \mathrm{~h}$ after SE, although CDK5-Y15 phosphorylation in astrocytes was unaltered. Furthermore, apocynin could not affect DRP1 S-616 phosphorylation in astrocytes. These findings indicated that $\mathrm{p} 47 \mathrm{Phox}$ may activate CDK5-mediated DRP1-616 phosphorylation in PV neurons, but not in astrocytes. Taken together, it is likely that CDK5 may be one of common kinases of DRP1-S616 in PV neurons (in the early stage) and astrocytes (in the later stage) following SE, but the up-steam activators of CDK5 may be different between PV neurons (p47Phox in the present study) and astrocytes (unknown). Further studies are needed to elucidate the signaling pathway for DRP1-S616 phosphorylation in astrocytes.

\section{CONCLUSION}

We propose that $\mathrm{p} 47 \mathrm{Phox} / \mathrm{CDK} 5 / \mathrm{DRP} 1$ axis may be one of the important upstream signal pathways for excessive mitochondrial fission, which leads to PV cell degeneration following SE. 


\section{AUTHOR CONTRIBUTIONS}

T-CK designed and supervised the project. J-EK and T-CK performed the experiments described in the manuscript and analyzed the data. J-EK and T-CK wrote the manuscript.

\section{ACKNOWLEDGMENTS}

This work was supported by the National Research Foundation of Korea (NRF) grants (No. 2009-0093812,

\section{REFERENCES}

Bedard, K., and Krause, K. H. (2007). The NOX family of ROS-generating NADPH oxidases: physiology and pathophysiology. Physiol. Rev. 87, 245-313. doi: 10.1152/physrev.00044.2005

Brandes, R. P., Weissmann, N., and Schroder, K. (2014). Nox family NADPH oxidases: molecular mechanisms of activation. Free Radic. Biol. Med. 76, 208-226. doi: 10.1016/j.freeradbiomed.2014.07.046

Cammarota, M., Losi, G., Chiavegato, A., Zonta, M., and Carmignoto, G. (2013). Fast spiking interneuron control of seizure propagation in a cortical slice model of focal epilepsy. J. Physiol. 591, 807-822. doi: 10.1113/jphysiol.2012.238154

Campello, S., and Scorrano, L. (2010). Mitochondrial shape changes: orchestrating cell pathophysiology. EMBO Rep. 11, 678-684. doi: 10.1038/embor.2010.115

Celio, M. R. (1990). Calbindin D-28k and parvalbumin in the rat nervous system. Neuroscience 35, 375-475. doi: 10.1016/0306-4522(90)90091-H

Chan, D. C. (2006). Mitochondrial fusion and fission in mammals. Annu. Rev. Cell Dev. Biol. 22, 79-99. doi: 10.1146/annurev.cellbio.22.010305.104638

Chen, H., and Chan, D. C. (2009). Mitochondrial dynamics-fusion, fission, movement and mitophagy-in neurodegenerative diseases. Hum. Mol. Genet. 18, R169-R176. doi: 10.1093/hmg/ddp326

Cherubini, M., Puigdellívol, M., Alberch, J., and Ginés, S. (2015). Cdk5-mediated mitochondrial fission: a key player in dopaminergic toxicity in Huntington's disease. Biochim. Biophys. Acta 1852, 2145-2160. doi: 10.1016/j.bbadis.2015. 06.025

Cheung, E. C., McBride, H. M., and Slack, R. S. (2007). Mitochondrial dynamics in the regulation of neuronal cell death. Apoptosis 12, 979-992. doi: 10.1007/ s10495-007-0745-5

Dang, D. K., Shin, E. J., Nam, Y., Ryoo, S., Jeong, J. H., Jang, C. G., et al. (2016). Apocynin prevents mitochondrial burdens, microglial activation, and pro-apoptosis induced by a toxic dose of methamphetamine in the striatum of mice via inhibition of p47phox activation by ERK. J. Neuroinflammation 13, 12 . doi: 10.1186/s12974-016-0478-x

Detmer, S. A., and Chan, D. C. (2007). Functions and dysfunctions of mitochondrial dynamics. Nat. Rev. Mol. Cell Biol. 8, 870-879. doi: 10.1038/ nrm2275

Di Maio, R., Mastroberardino, P. G., Hu, X., Montero, L., and Greenamyre, J. T. (2011). Pilocarpine alters NMDA receptor expression and function in hippocampal neurons: NADPH oxidase and ERK1/2 mechanisms. Neurobiol. Dis. 42, 482-495. doi: 10.1016/j.nbd.2011.02.012

DuBoff, B., Götz, J., and Feany, M. B. (2012). Tau promotes neurodegeneration via DRP1 mislocalization in vivo. Neuron 75, 618-632. doi: 10.1016/j.neuron.2012. 06.026

Elgueta, C., Köhler, J., and Bartos, M. (2015). Persistent discharges in dentate gyrus perisoma-inhibiting interneurons require hyperpolarization-activated cyclic nucleotide-gated channel activation. J. Neurosci. 35, 4131-4139. doi: 10.1523/ JNEUROSCI.3671-14.2015

Hyun, H. W., Ko, A. R., and Kang, T. C. (2016). Mitochondrial translocation of high mobility group box 1 facilitates LIM kinase 2-mediated programmed necrotic neuronal death. Front. Cell. Neurosci. 10:99. doi: 10.3389/fncel.2016. 00099

Hyun, H. W., Min, S. J., and Kim, J. E. (2017). CDK5 inhibitors prevent astroglial apoptosis and reactive astrogliosis by regulating PKA and DRP1
2013R1A6A3A04058272, 2015R1A2A2A01003539). The funders had no role in study design, data collection and analysis, decision to publish, or preparation of the manuscript.

\section{SUPPLEMENTARY MATERIAL}

The Supplementary Material for this article can be found online at: http://journal.frontiersin.org/article/10.3389/fncel. 2017.00267/full\#supplementary-material

phosphorylations in the rat hippocampus. Neurosci. Res. 119, 24-37. doi: 10.1016/j.neures.2017.01.006

Jahani-Asl, A., Cheung, E. C., Neuspiel, M., MacLaurin, J. G., Fortin, A., Park, D. S., et al. (2007). Mitofusin 2 protects cerebellar granule neurons against injury-induced cell death. J. Biol. Chem. 282, 23788-23798. doi: 10.1074/jbc. M703812200

Jahani-Asl, A., Huang, E., Irrcher, I., Rashidian, J., Ishihara, N., Lagace, D. C., et al. (2015). CDK5 phosphorylates DRP1 and drives mitochondrial defects in NMDA-induced neuronal death. Hum. Mol. Genet. 24, 4573-4583. doi: $10.1093 / \mathrm{hmg} / \mathrm{ddv} 188$

Kang, T. C., Kim, D. S., Kwak, S. E., Kim, J. E., Won, M. H., Kim, D. W., et al. (2006). Epileptogenic roles of astroglial death and regeneration in the dentate gyrus of experimental temporal lobe epilepsy. Glia 54, 258-271. doi: 10.1002/glia. 20380

Kashatus, D. F., Lim, K. H., Brady, D. C., Pershing, N. L., Cox, A. D., and Counter, C. M. (2011). RALA and RALBP1 regulate mitochondrial fission at mitosis. Nat. Cell Biol. 13, 1108-1115. doi: 10.1038/ncb2310

Kim, D. S., Kim, J. E., Kwak, S. E., Choi, K. C., Kim, D. W., Kwon, O. S., et al. (2008). Spatiotemporal characteristics of astroglial death in the rat hippocampoentorhinal complex following pilocarpine-induced status epilepticus. J. Comp. Neurol. 511, 581-598. doi: 10.1002/cne.21851

Kim, J. E., Ryu, H. J., and Kang, T. C. (2011). P2X7 receptor activation ameliorates CA3 neuronal damage via a tumor necrosis factora-mediated pathway in the rat hippocampus following status epilepticus. J. Neuroinflammation 8:62. doi: 10.1186/1742-2094-8-62

Kim, J. E., Ryu, H. J., Kim, M. J., and Kang, T. C. (2014). LIM kinase-2 induces programmed necrotic neuronal death via dysfunction of DRP1-mediated mitochondrial fission. Cell Death Differ. 21, 1036-1049. doi: 10.1038/cdd. 2014.17

Kim, Y. J., and Kang, T. C. (2015). The role of TRPC6 in seizure susceptibility and seizure-related neuronal damage in the rat dentate gyrus. Neuroscience 307 , 215-230. doi: 10.1016/j.neuroscience.2015.08.054

Ko, A. R., Hyun, H. W., Min, S. J., and Kim, J. E. (2016). The differential DRP1 phosphorylation and mitochondrial dynamics in the regional specific astroglial death induced by status epilepticus. Front. Cell. Neurosci. 10:124. doi: 10.3389/ fncel.2016.00124

Ko, A. R., Hyun, H. W., Min, S. J., Kim, J. E., and Kang, T. C. (2015). Endothelin-1 induces LIMK2-mediated programmed necrotic neuronal death independent of NOS activity. Mol. Brain 8, 58. doi: 10.1186/s13041-0150149-3

Lai, K. O., and Ip, N. Y. (2009). Recent advances in understanding the roles of Cdk5 in synaptic plasticity. Biochim. Biophys. Acta 1792, 741-745. doi: 10.1016/ j.bbadis.2009.05.001

Mathern, G. W., Babb, T. L., Vickrey, B. G., Melendez, M., and Pretorius, J. K. (1995). The clinical-pathogenic mechanisms of hippocampal neuron loss and surgical outcomes in temporal lobe epilepsy. Brain 118, 105-118. doi: 10.1093/ brain/118.1.105

Ordy, J. M., Wengenack, T. M., Bialobok, P., Coleman, P. D., Rodier, P., Baggs, R. B., et al. (1993). Selective vulnerability and early progression of hippocampal CA1 pyramidal cell degeneration and GFAP-positive astrocyte reactivity in the rat four-vessel occlusion model of transient global ischemia. Exp. Neurol. 119, 128-139. doi: 10.1006/exnr.1993.1014 
Parone, P. A., Da Cruz, S., Tondera, D., Mattenberger, Y., James, D. I., Maechler, P., et al. (2008). Preventing mitochondrial fission impairs mitochondrial function and leads to loss of mitochondrial DNA. PLoS ONE 3:e3257. doi: 10.1371/ journal.pone.0003257

Patel, M., Li, Q. Y., Chang, L. Y., Crapo, J., and Liang, L. P. (2005). Activation of NADPH oxidase and extracellular superoxide production in seizure-induced hippocampal damage. J. Neurochem. 92, 123-131. doi: 10.1111/j.1471-4159. 2004.02838.x

Pestana, R. R., Kinjo, E. R., Hernandes, M. S., and Britto, L. R. (2010). Reactive oxygen species generated by NADPH oxidase are involved in neurodegeneration in the pilocarpine model of temporal lobe epilepsy. Neurosci. Lett. 484, 187-191. doi: 10.1016/j.neulet.2010.08.049

Qiu, L. L., Luo, D., Zhang, H., Shi, Y. S., Li, Y. J., Wu, D., et al. (2016). Nox-2-mediated phenotype loss of hippocampal parvalbumin interneurons might contribute to postoperative cognitive decline in aging mice. Front. Aging Neurosci. 8:234. doi: 10.3389/fnagi.2016.00234

Qiu, X., Cao, L., Yang, X., Zhao, X., Liu, X., Han, Y., et al. (2013). Role of mitochondrial fission in neuronal injury in pilocarpine-induced epileptic rats. Neuroscience 245, 157-165. doi: 10.1016/j.neuroscience.2013.04.019

Rintoul, G. L., and Reynolds, I. J. (2010). Mitochondrial trafficking and morphology in neuronal injury. Biochim. Biophys. Acta 1802, 143-150. doi: 10.1016/j.bbadis. 2009.09.005

Ryu, H. J., Kim, J. E., Yeo, S. I., Kim, M. J., Jo, S. M., and Kang, T. C. (2011). ReLA/P65-serine 536 nuclear factor-kappa B phosphorylation is related to vulnerability to status epilepticus in the rat hippocampus. Neuroscience 187, 93-102. doi: 10.1016/j.neuroscience.2011.04.048

Sloviter, R. S. (1991). Permanently altered hippocampal structure, excitability, and inhibition after experimental status epilepticus in the rat: the "dormant basket cell" hypothesis and its possible relevance to temporal lobe epilepsy. Hippocampus 1, 41-66. doi: 10.1002/hipo.450010106

Sloviter, R. S., Zappone, C. A., Harvey, B. D., Bumanglag, A. V., Bender, R. A., and Frotscher, M. (2003). "Dormant basket cell" hypothesis revisited: relative vulnerabilities of dentate gyrus mossy cells and inhibitory interneurons after hippocampal status epilepticus in the rat. J. Comp. Neurol. 459, 44-76. doi: 10.1002/cne.10630

Smirnova, E., Griparic, L., Shurland, D. L., and van der Bliek, A. M. (2001). Dynamin-related protein Drp1 is required for mitochondrial division in mammalian cells. Mol. Biol. Cell 12, 2245-2256. doi: 10.1091/mbc.12.8.2245

Soukupová, M., Binaschi, A., Falcicchia, C., Zucchini, S., Roncon, P., Palma, E., et al. (2014). Impairment of GABA release in the hippocampus at the time of the first spontaneous seizure in the pilocarpine model of temporal lobe epilepsy. Exp. Neurol. 257, 39-49. doi: 10.1016/j.expneurol.2014.04.014

Stolk, J., Hiltermann, T. J., Dijkman, J. H., and Verhoeven, A. J. (1994). Characteristics of the inhibition of NADPH oxidase activation in neutrophils by apocynin, a methoxy-substituted catechol. Am. J. Respir. Cell Mol. Biol. 11, 95-102. doi: 10.1165/ajrcmb.11.1.8018341
Sun, K. H., de Pablo, Y., Vincent, F., and Shah, K. (2008). Deregulated Cdk5 promotes oxidative stress and mitochondrial dysfunction. J. Neurochem. 107, 265-278. doi: 10.1111/j.1471-4159.2008.05616.x

't Hart, B. A., Simons, J. M., Knaan-Shanzer, S., Bakker, N. P., and Labadie, R. P. (1990). Antiarthritic activity of the newly developed neutrophil oxidative burst antagonist apocynin. Free Radic. Biol. Med. 9, 127-131. doi: 10.1016/08915849(90)90115-Y

Wittner, L., Maglóczky, Z., Borhegyi, Z., Halász, P., Tóth, S., Eross, L., et al. (2001). Preservation of perisomatic inhibitory input of granule cells in the epileptic human dentate gyrus. Neuroscience 108, 587-600. doi: 10.1016/S0306-4522(01) 00446-8

Xie, N., Wang, C., Lian, Y., Zhang, H., Wu, C., and Zhang, Q. (2013). A selective inhibitor of Drp1, mdivi-1, protects against cell death of hippocampal neurons in pilocarpine-induced seizures in rats. Neurosci. Lett. 545, 64-68. doi: 10.1016/ j.neulet.2013.04.026

Xie, Q., Wu, Q., Horbinski, C. M., Flavahan, W. A., Yang, K., Zhou, W., et al. (2015). Mitochondrial control by DRP1 in brain tumor initiating cells. Nat. Neurosci. 18, 501-510. doi: 10.1038/nn.3960

Youle, R. J., and Karbowski, M. (2005). Mitochondrial fission in apoptosis. Nat. Rev. Mol. Cell Biol. 6, 657-663. doi: 10.1038/nrm1697

Yu, T., Robotham, J. L., and Yoon, Y. (2006). Increased production of reactive oxygen species in hyperglycemic conditions requires dynamic change of mitochondrial morphology. Proc. Natl. Acad. Sci. U.S.A. 103, 2653-2658. doi: 10.1073/pnas.0511154103

Yu, T., Sheu, S. S., Robotham, J. L., and Yoon, Y. (2008). Mitochondrial fission mediates high glucose-induced cell death through elevated production of reactive oxygen species. Cardiovasc. Res. 79, 341-351. doi: 10.1093/cvr/cvn104

Zhang, H., Sun, X. R., Wang, J., Zhang, Z. Z., Zhao, H. T., Li, H. H., et al. (2016). Reactive oxygen species-mediated loss of phenotype of parvalbumin interneurons contributes to long-term cognitive impairments after repeated neonatal ketamine exposures. Neurotox. Res. 30, 593-605. doi: 10.1007/s12640016-9653-1

Zhu, X., Su, B., Wang, X., Smith, M. A., and Perry, G. (2007). Causes of oxidative stress in Alzheimer disease. Cell. Mol. Life Sci. 64, 2202-2210. doi: 10.1007/ s00018-007-7218-4

Conflict of Interest Statement: The authors declare that the research was conducted in the absence of any commercial or financial relationships that could be construed as a potential conflict of interest.

Copyright (c) 2017 Kim and Kang. This is an open-access article distributed under the terms of the Creative Commons Attribution License (CC BY). The use, distribution or reproduction in other forums is permitted, provided the original author(s) or licensor are credited and that the original publication in this journal is cited, in accordance with accepted academic practice. No use, distribution or reproduction is permitted which does not comply with these terms. 